\title{
Impacto da tecnologia de informação na gestão de pequenas empresas
}

\author{
Lairce Castanhera Beraldi \\ Vice-coordenadora do Núcleo de Pesquisa em Pequenas \\ Empresa NúPPe/UNIRP. Doutoranda da Escola de \\ Engenharia da USP - São Carlos. \\ e-mail: lberaldi@zaz.com.br \\ Edmundo Escrivão Filho \\ Professor doutor da Escola de Engenharia da USP-São Carlos \\ - Departamento de Engenharia de Produção. \\ e-mail: edesfi@prod.eesc.sc.usp.br
}

\section{Resumo}

Dentro do novo contexto empresarial criado pela globalização, a tecnologia de informação fornece possibilidades de permanente atualização e integração do negócio, visto que potencializa os processos de tratamento, disseminação e transferência de informações. Essa tecnologia tão importante parece ainda não ter alcançado plenamente as pequenas empresas que, no geral, não possuem sistemas informatizados. Para verificar a situação atual do emprego da tecnologia de informação em pequenas empresas, foi realizado um estudo em dez empresas com número de funcionários entre 20 e 99. Verificou-se que a pequena empresa não percebe mudanças significativas em suas atividades após a informatização.

\section{Palavras-chave}

Tecnologia de informação; Gestão de pequena empresa; Competitividade.

\section{Information technology impact in the small company management}

\begin{abstract}
Within the new managerial context created by globalization, information technology offers many possibilities for continuous business modernization and integration as it reinforces the process of the treatment, dissemination and transfer of information. This highly important technology, however, is apparently not yet widely employed by small companies, which generally do not have computerized systems. In view of this fact, a survey of ten companies that employ from 20 to 99 people was recently made to examine the current situation of the use of information technology in small companies. This survey brought to light the fact that small companies have not significantly modified their activities as a result of informatization.
\end{abstract}

\section{Keywords}

Information technology; Small company management; Competitiveness.

Artigo aceito para publicação em 17/01/2000

\section{APRESENTAÇÃO}

Pela primeira vez na história empresarial, as empresas de menor porte podem competir com ferramentas ou estratégias tão potentes quanto às das grandes corporações. A informação, que marcará a competição daqui para a frente, é um recurso disponível e democrático ${ }^{4}$. Mas, para que as ferramentas, estratégias e informações sejam bem utilizadas, é preciso definir previamente os rumos da empresa.

Segundo uma pesquisa realizada pela Mcon Consultoria Empresarial $^{4}$, abrangendo 150 empresas de pequeno porte, cerca de $90 \%$ das empresas pesquisadas contam com computadores. Entretanto, a maioria dessas empresas não sente efeitos positivos na informatização (quadro 1, a seguir).

Tais resultados demonstram que uma ferramenta tão poderosa como a tecnologia de informação ainda não está a serviço das pequenas empresas.

Segundo o autor da pesquisa, isso pode ser atribuído a uma questão de desvio de foco, pois muitas dessas empresas não definem para que serão usados os equipamentos e sistemas antes de comprá-los; máquinas e softwares, em si, nada resolvem, se não forem absolutamente adequados para uma finalidade específica ${ }^{3,4}$.

\section{APLICAÇÃO DA TECNOLOGIA DE INFORMAÇÃO NA PEQUENA EMPRESA}

As pequenas empresas no geral não possuem sistemas informatizados, ou seja, seus controles são feitos quase que exclusivamente por meio de papeladas intermináveis.

Contudo, o custo cada vez menor dos computadores e a onda de gestão integrada por software parecem incentivar cada vez mais o pequeno empresário a investir pesado nesse setor em busca de melhor desempenho da empresa com relação aos concorrentes.

Esse tipo de investimento pode ser muito desastroso para a empresa, caso ela e os funcionários não estejam totalmente capacitados a lidar com essa nova tecnologia. 
É aconselhável uma avaliação antes de investir nesses equipamentos, levando-se em conta alguns aspectos, como a quantidade de clientes e fornecedores, as encomendas, o orçamento, o estoque, as análises financeiras, a quantidade de empregados, a quantidade de registros e documentos etc.

Levantada a necessidade de implantação de um sistema de informação, a empresa deverá avaliar o que realmente precisa, para assim comparar todos os pacotes oferecidos no mercado (custo/benefício) e, então, escolher um sistema mais eficaz para sua gestão.

Para que o processo de informatização seja bemsucedido, deve-se seguir uma abordagem dividida em etapas ordenadas ${ }^{1,2,5}$. Uma abordagem que pode ser utilizada é apresentada a seguir:

Etapa 1: Aprenda sobre informatização visitando empresas similares que já tenham sofrido o processo de informatização de suas atividades.

Etapa 2: Contrate pessoas especializadas, se necessário, pois, quanto melhor for a avaliação inicial, maiores os benefícios que poderão ser alcançados.

Etapa 3: Analise o sistema manual utilizado atualmente pela empresa, envolvendo as pessoas responsáveis por cada processo.

Etapa 4: Identifique os processos que devem ser informatizados, as possíveis melhorias e necessidades informacionais desses processos.

Etapa 5: Analise a adoção de rede interna (talvez uma intranet), a criação de uma rede que possibilite a comunicação com clientes, fornecedores e outros (extranet) e a conexão para comunicação externa (internet).

Etapa 6: Defina claramente as expectativas para a informatização (grau, prazos, custos, benefícios esperados etc.).

Etapa 7: Compare os custos e os benefícios - lembre-se de levar em consideração os custos e benefícios indiretos.

Etapa 8: Estabeleça um cronograma para a informatização.

Etapa 9: Prepare seus funcionários para a informatização. Promova a conscientização da necessidade de informatização, mostre os benefícios que podem ser alcançados, treine as pessoas envolvidas, discuta as
QUADRO 1

Opinião de algumas empresas sobre questões de informatização ${ }^{4}$

Questões Percentual

Não houve aumento nos lucros $31 \%$

Se houve lucro, foi pequeno $22 \%$

Nada mudou no patamar de vendas

Pouca melhoria $48 \%$ $23 \%$

O uso do computador não influencia na competitividade $21 \%$ Proporciona ligeira melhora na competitividade

necessidades de mudanças e a melhor maneira de fazê-las com todos os envolvidos etc.

Etapa 10: Defina e obtenha primeiramente os softwares necessários e depois o hardware apropriado para executálos.

Etapa 11: Inicie o processo de informatização o mais rápido possível e respeite, se possível, os prazos estabelecidos no cronograma.

Outro ponto importante para um processo de informatização bem-sucedido é a manutenção dos softwares que irão tratar as informações, pois alguns problemas no software não são descobertos antes que ele esteja sendo realmente utilizado.

\section{Vantagens da informatização em pequenas empresas}

Uma empresa com um sistema totalmente informatizado, funcionando eficiente e eficazmente, proporcionará grandes vantagens, seja em relação ao tempo otimizado, à organização, à facilidade de obtenção de informações, à previsão e muitos outros aspectos que contribuirão para o sucesso da pequena empresa.

Dessa forma, a informatização das pequenas empresas possibilita que elas ganhem eficiência e eficácia melhorando, assim, sua competitividade e aumentando sua lucratividade ${ }^{4,5}$.

Segundo Zimmerer, ${ }^{5}$ algumas das vantagens que podem ser citadas sobre a informatização das pequenas empresas são descritas a seguir:

- melhora as informações para tomada de decisão;

- automatiza as tarefas rotineiras;

- melhora o controle interno das operações; 
- melhora o atendimento ao cliente;

- aumenta a capacidade de reconhecer problemas mais cedo;

- ajuda o gerente a testar algumas decisões antes de colocálas em prática;

- melhora o processo produtivo;

- aumenta a produtividade e competitividade.

\section{PESQUISA SOBRE O EMPREGO DA TECNOLOGIA DE INFORMAÇÃO NA PEQUENA EMPRESA}

Os autores realizaram uma pesquisa sobre "Informatização nas Pequenas Empresas", no período de fevereiro a outubro de 1999, buscando levantar dados empíricos sobre a situação na cidade de São José do Rio Preto, Estado de São Paulo, pois ela apresenta uma grande atratividade para instalações de novas indústrias devido à sua localização e facilidade de escoamento de produções, por meio de rodovias e hidrovias. Além disso, a passagem do gasoduto Brasil-Bolívia pela região reduzirá o custo com energia, o que deve ser considerado pelas indústrias em geral.

Foram visitadas 10 empresas, com número de funcionários entre 20 e 99, nos seguintes ramos de atividade: confecção de roupas, produtos farmacêuticos e higiene hospitalar, metalúrgica, artefatos de plástico, empacotamento e comércio de produtos agrícolas, fabricação e comércio de jóias, comércio de vidros e comércio de derivado de petróleo (gás de cozinha).

A pesquisa teve como objetivo identificar algumas características sobre o uso da tecnologia de informação em pequenas empresas. No quadro 2, é apresentado um

\section{ANÁLISE DOS RESULTADOS}

\section{O emprego da tecnologia de informação na pequena empresa}

A grande motivação para que as pequenas empresas estejam buscando adquirir recursos da tecnologia de informação é a sua sobrevivência num mercado cada vez mais global e competitivo. Essas empresas esperam que, com a aquisição de modernas tecnologias para tratamento de informação, sua agilidade e flexibilidade melhorem significativamente, além do aumento da qualidade de seus produtos.
QUADRO 2

Resumo das informações obtidas a partir do trabalho de campo

Questões levantadas

Sim

Não

As pequenas empresas possuem

recursos de TI?

$100 \%$

$0 \%$

As pequenas empresas planejaram

a aquisição e uso da TI?

$6 \%$

$94 \%$

Os recursos de TI são bem aproveitados

pelas pequenas empresas? $\quad 6 \%$

$94 \%$

É realizado treinamento para os

usuários dos recursos de TI?

$6 \%$

$94 \%$

O desenvolvimento de software é

terceirizado?

$94 \%$

$6 \%$

As pequenas empresas

percebem

benefícios no uso de TI?

$\begin{array}{ccc}\begin{array}{c}\text { Nenhum } \\ 33 \%\end{array} & \begin{array}{c}\text { Pouco } \\ 54 \%\end{array} & \begin{array}{c}\text { Muito } \\ 13 \%\end{array} \\ \text { Sim } & & \text { Não } \\ & & 0 \% \\ 100 \% & 27 \% \\ 73 \% & 54 \% \\ 46 \% & 87 \% \\ 13 \% & \end{array}$

Quais os recursos de TI

usados nas pequenas

empresas?

Microcomputadores

Redes de computadores

Internet

$13 \%$

Não

Questões levantadas

Sim

$60 \%$

Sistemas de gerenciamento

de banco de dados

$40 \%$

Sistemas integrados de gestão

$0 \%$

$100 \%$

Sistema operacional

DOS + Win95
ou 98
$74 \%$

Win NT

Win95

Win98

\begin{tabular}{lcccc} 
& $\begin{array}{c}\text { ou } 98 \\
74 \%\end{array}$ & $0 \%$ & $20 \%$ & $0 \%$ \\
& & & & \\
$\begin{array}{l}\text { Sistema gerenciador } \\
\text { de rede de } \\
\text { computadores } \\
\text { (avaliado de } \\
\text { acordo com os }\end{array}$ & $\begin{array}{c}\text { Novell/ } \\
\text { Win NT }\end{array}$ & Novell & Win NT & Win 95 \\
$\begin{array}{l}73 \% \text { que } \\
\text { possuem rede) }\end{array}$ & $9 \%$ & $64 \%$ & $18 \%$ & $9 \%$ \\
& & & & \\
$\begin{array}{l}\text { Sistemas para } \\
\text { informatização }\end{array}$ & $\begin{array}{c}\text { Escritório } \\
74 \%\end{array}$ & $\begin{array}{c}\text { Produção } \\
0 \%\end{array}$ & $\begin{array}{c}\text { Escr./Prod. Outros } \\
20 \%\end{array}$ & $6 \%$ \\
\hline
\end{tabular}


Desse modo, as pequenas empresas estão, na maior parte dos casos estudados, procurando adquirir recursos de tecnologia para tratamento de informação. Entretanto, a aquisição desses recursos não é planejada, e eles não são bem aproveitados devido, principalmente, à falta de conhecimento de sua potencialidade, dificuldades de aquisição de itens complementares e falta de treinamento para os usuários. Devido a essas deficiências e dificuldades, as empresas não conseguem grandes benefícios no uso da tecnologia de informação.

Pôde-se verificar que o conhecimento sobre o assunto é muito restrito, pois a maioria das empresas terceiriza o desenvolvimento de softwares e nem sequer conhece os recursos que tem disponível, agravando ainda mais o mau aproveitamento e o baixo retorno dos recursos apresentados após a informatização.

Outra informação importante mostrada pela pesquisa é que as pequenas empresas investem muito mais em hardware do que em software, a média de microcomputador por empresa é de 8,8 unidades, e eles estão alocados em sua maioria na parte administrativa das empresas, quando hoje o inverso seria o ideal. O único tipo de software que recebe um pouco mais de investimento é o de informatização de administração: contabilidade, folha de pagamento, contas a pagar e a receber, financeiro, entre outros. Nenhuma das empresas pesquisadas possui sistema integrado de gestão tão necessário para o controle dos negócios da empresa, além de outros recursos que poderiam ajudar a alavancar sua produtividade e competitividade.

Diante desse contexto de implementação da tecnologia de informação, a pequena empresa não observa grandes mudanças após a informatização, e a maioria não enxerga grandes benefícios no seu uso.

Outro dado interessante é que, de acordo com esse estudo, apenas em algumas empresas o proprietário responde pelo setor de informática da empresa. Na maioria dos casos, não existe uma pessoa responsável por esta área dentro da empresa, geralmente é o usuário (o funcionário que utiliza o microcomputador), quem mais conhece sobre a situação dos microcomputadores e softwares da empresa.

\section{A gestão da pequena empresa}

Dentro do atual contexto de mercado, a pequena empresa necessita de um sistema informatizado para controlar sua gestão. Contudo, apesar de esse instrumento ser de grande utilidade para se alcançar o sucesso, o pequeno empresário deve estar atento a algumas questões.
O primeiro passo é fazer um dimensionamento da empresa no contexto atual e também uma dimensão planejada para o futuro, para que dessa forma possam-se adquirir equipamentos adequados às necessidades.

É indicada a orientação de pessoas tecnicamente capacitadas, tanto para o dimensionamento, quanto para a escolha dos equipamentos e softwares que serão implantados. Em alguns casos, é melhor procurar empresas que elaborem sistemas personalizados, em vez da compra de pacotes comerciais prontos.

A partir da informatização, a pequena empresa pode obter uma série de vantagens, caso o processo seja efetuado de maneira correta, pois a informatização promove o enxugamento da empresa (papéis, fichas, anotações, pastas, cadernos, folhetos, arquivos); a eliminação das atividade burocráticas, tais como elaboração de manual de fichas de fornecedores e clientes, emissão de notas fiscais, liberação de pedidos, cadastro de funcionários, consulta à legislação, que podem ser facilmente feitas no computador; o aumento da agilidade, segurança, integridade e exatidão das informações levantadas, além, é claro, da redução das despesas em todos os setores envolvidos. Também auxilia no aperfeiçoamento da administração geral da empresa, da administração de marketing, do planejamento e controle da produção, das demonstrações financeiras, das previsões orçamentárias, das análises de investimentos e de custos.

\section{CONCLUSÃO}

A tecnologia de informação é um recurso de difícil acesso para as pequenas empresas, seu custo de aquisição é considerado alto, e existe uma grande dificuldade de adequação e utilização desses recursos.

As pequenas empresas têm dificuldade em obter financiamento, por falta de linhas de crédito adequadas ou por dificuldades em preencher as exigências necessárias. Sendo assim, é preciso criar linhas de financiamento voltadas para aquisição da tecnologia de informação com menores exigências para que a pequena empresa possa adquirir essa tecnologia e o conhecimento necessário para sua eficaz e eficiente utilização.

Quando a pequena empresa consegue adquirir essa tecnologia, geralmente não efetua um levantamento adequado de suas necessidades atuais e um planejamento das necessidades futuras. Assim, normalmente valorizam mais o hardware do que o software, quando deveria acontecer o inverso. Isso pode ser visto pela média de 8,8 microcomputadores por empresa, uma média boa, levando- 
se em conta o tamanho das empresas e considerando-se, também, a insatisfação pelo uso dos recursos de informática.

Outro fator importante é que grande parte das pequenas empresas utiliza serviços de terceiros para implementar alguns sistemas de informatização de escritório e, na maioria dos casos, não fica satisfeita com os serviços prestados. Como resultado disso, temos o desinteresse cada vez maior, por parte da pequena empresa, em usar tecnologia de informação, solidificando assim a idéia de que é melhor não utilizar os recursos da tecnologia de informação, já que não temos capital humano para esse trabalho.

Todos esses fatores contribuem para formar o quadro da informatização deficiente das pequenas empresas: falta de conhecimento da potencialidade da tecnologia de informação, pouco conhecimento dos recursos que essa tecnologia oferece, falta de treinamento dos usuários e escassez de consultorias preparadas para atender às condições apresentadas por esse mercado.

\section{REFERÊNCIAS BIBLIOGRÁFICAS}

1. GATES, B. Como uma pequena empresa pode competir? Jornal Folha de São Paulo: caderno de informática. Quarta-feira, 17 de junho de 1998, p.6.

2. LONGENECKER, J. G et al. Administração de pequenas empresas: ênfase na gerência empresarial. São Paulo: Makron Books do Brasil, 1997.

3. POZZEBON, M. et al. Pela integração da inteligência competitiva nos Enterprise Information Systems (EIS). Ciência da Informação, n.3, v.26, setembro/dezembro de 1997, p.243-254.

4. SANTOS, M. Fora de Foco: por que boa parte das pequenas empresas não consegue tirar vantagens efetivas da informática e da informação. Pequenas Empresas Grandes Negócios, n.108, ano X, fevereiro de 1998, p.60-61.

5. ZIMMERER, T. W.; SCARBOROUGH, N. M. Essentials of small business management. Macmillan College Publishing Company, 1994.

\section{BIBLIOGRAFIA RECOMENDADA}

1. CAVAlCANTI, M.; FARAH, O. E.; MEllo, A. A. A. Diagnóstico organizacional: uma metodologia para pequenas e médias empresas. São Paulo: Edições Loyola, 1981.

2. CASH, J. I.; ECCLES, R. G.; NOHRIA, N.; NOLAN, R. L. Building the information-age organization: structure, control, and information technologies. Chicago: Richard D. Irwin Inc, 1994.

3. CHER, R. A gerência da pequena e média empresa. São Paulo: Maltese, 1991.

4. D'ERCOLE, R. Dinheiro a conta-gotas. Pequenas Empresas Grandes Negócios, n.110, ano X, março de 1998, p.58-61.

5. EARL, M. Information management: the strategic dimension. Oxford:Clarendon Press, 1990.

6. FElisminO, D. Saindo do Sufoco. Revista das Pequenas e Médias Empresas, n.3, ano 1, maio de 1996, p.28-29.

7. GLYNN, K.; KOENIG, M. E. D.; COLLEGE, R. Small business and information technology. Annual Review of Information Science and Technology, v. 30, 1995, p.251-280.

8. OliVEIRA, M. M. A vitalidade das pequenas. Pequenas Empresas Grandes Negócios, n.110, ano X, março de 1998, p.40-44.

9. SANTOS, R. N. M. Sistemas de informações estratégicas para a vitalidade da empresa. Ciência da Informaçãoo, n.1, v.25, jan/abr de 1996, p.12-14.

10. TAPSCOTT, D.; CASTON, A. Mudança de paradigma: a nova promessa da tecnologia de informação. São Paulo: Makron Books do Brasil, 1995.

11. WOOD, J. L.; STASCH, S. F. How small share firms can uncover winning strategies. The Journal of Business Strategies, n.5, v.9, setembro/outubro de 1988, p.26-31. 